\title{
Dos aplicaciones del modelo melodramático: Manuela Sáenz y Leona Vicario en el imaginario contemporáneo sobre las independencias*
}

\author{
Duas aplicações do modelo melodramático: \\ Manuela Sáenz e Leona Vicario no imaginário contemporâneo sobre as independências
}

\author{
Carolina Pizarro Cortés \\ Universidade de Santiago do Chile - Santiago do Chile - Chile
}

$\diamond$

\begin{abstract}
Resumen: Este trabajo propone considerar el melodrama como un modelo que dota de significados a las obras que los contienen, más allá de la representación del conflicto amoroso. Se lo considera, dentro del contexto latinoamericano, como una forma sui generis que contribuye desde su connatural ambivalencia a la interpretación del pasado histórico, transitando entre diversos modos de representación. Esta potencialidad del modelo se explora en un conjunto variado de obras ficcionales contemporáneas que representan a dos mujeres de las gestas independentistas, Manuela Sáenz y Leona Vicario, mostrando la forma en que dialogan críticamente con la historiografía latinoamericana y modifican, desde las estrategias narrativas del melodrama, sus sentidos.

Palabras clave: Melodrama; Independencia; Manuela Sáenz; Leona Vicario

Resumo: Este trabalho propõe considerar o melodrama como um modelo que dota significados às obras que os contêm, além da representação do conflito amoroso. Dentro do contexto latino-americano é considerado como uma forma sui generis que contribui com sua natural ambivalencia à interpretação do passado histórico, transitando entre diversos modos de representação. Essa potencialidade do modelo é explorada em um conjunto variado de obras ficcionais contemporâneas que representam duas mulheres das gestas independentistas, Manuela Sáenz e Leona Vicário, mostrando a forma com que dialogam críticamente com a historiografía latino-americana e modificam, pelas estratégias narrativas do melodrama, seus sentidos.
\end{abstract}

Palavras-chave: Melodrama; Independencia; Manuela Sáenz; Leona Vicario

1. Una de las facetas del comparatismo que resulta interesante explorar es la forma en que algunos modelos de representación transitan entre distintos géneros artísticos. Así como hay temas que se repiten en obras plasmadas en formatos y soportes diferentes, muchas veces estableciéndose entre ellas relaciones intermediales, es posible pesquisar también la repetición de estructuras, las que generan sentidos similares en representaciones que no comparten una misma materialidad. Ello permite sostener, a mi juicio, que la coincidencia de dichos modelos o estructuras da cuenta de formas de imaginación

\footnotetext{
* Trabajo desarrollado dentro del marco del Proyecto Fondecyt de iniciación $\mathrm{n}^{\circ}$ 11110361, "La representación del sujeto en el imaginario independentista contemporáneo"
}

confluyentes, y que son estas formas las que contribuyen a producir sentidos análogos, que se espejean y refuerzan. Una de estas estructuras es el melodrama, suerte de plantilla transgenérica y transmedial, que se encuentra operando en la base de obras literarias de distinto género y también en obras visuales, en la música y en el cine.

De acuerdo con Peter Brooks, el melodrama nace en la Francia del siglo XIX, en el periodo posrevolucionario, como una forma teatral:

The Word melodrama means, originally, a drama accompanied by music. It appears to have first been used in this sense by Rousseau, to describe a play in wich he sought a new emotional expressivity through the mixture of spoken soliloquy, antomime, and orchestral accompaniment (BROOKS, 1976, p. 12). 
Este nuevo género, que responde la crisis de sentido que deja tras de sí la Ilustración, se refleja luego en otras formas literarias, como la novela, que hacen uso de su teatralidad, maniqueísmo y exageración. Por ello Herlinghaus, siguiendo a Brooks, define melodrama no como tema o conjunto de temas o géneros, sino como "una matriz de la imaginación teatral y narrativa que ayuda a producir sentido en medio de las experiencias cotidianas de individuos y grupos sociales diversos" (HERLINGHAUS, 2002, p. 23, con cursivas en el original).

En este trabajo me propongo explorar una de las posibilidades del melodrama o, si se prefiere, de la imaginación melodramática, lo que implica considerarla como formato estructurante de un grupo de representaciones artísticas que recuperan, para reelaborarlos, momentos y personajes históricos. Si fuese posible ampliar la teoría de los modos de entramado del discurso histórico que distingue Hayden White, una de las inclusiones que podría resultar fructífera es la de la trama melodramática1. Queda aún pendiente su constatación en ejemplos tomados de la historiografía; sin embargo, ya se ha visto su operación en el campo de la narrativa ficcional ${ }^{2}$. Quisiera extremar estos ejercicios críticos, para proponer que el melodrama funciona en un conjunto de representaciones contemporáneas como una estructura transmedial -como decíamos más arriba- que interviene de un modo muy particular el sentido de algunos de los lugares comunes de la historiografía latinoamericana.

Para mostrar el funcionamiento de la estructura melodramática me valdré de un conjunto de obras en las que se representa el genio y la figura de las heroínas de la independencia latinoamericana; pues así como hay un

\footnotetext{
En su análisis del discurso histórico, White distingue cuatro modos de explicación por la trama que serían los más frecuentes en la historiografía del siglo XIX: la tragedia, la comedia, el romance y la ironía. Estas formas discursivas funcionarían como bases estructurales de los relatos históricos y tendrían injerencia directa en su sentido: "Dado que ningún determinado conjunto de secuencia de acontecimientos reales es intrínsecamente trágico, cómico o propio de la farsa, etc., sino que puede constituirse como tal sólo en virtud de imponer la estructura de un determinado tipo de relato a los acontecimientos, es la elección del tipo de relato y su imposición lo que dota de significado a éstos" (WHITE, 1992, p. 61).

2 Esta es la interpretación que Cyntia Soto propone con notable acierto para la novela Mapocho, de la chilena Nona Fernández.

3 En el caso de las obras analizadas en este trabajo, debemos consignar una suerte de doble filiación: se trata de representaciones que son tanto populares como masivas. Al respecto, resulta iluminadora la mirada de Salvador Alfaro: "Si 'la cultura de masas no es algo completamente externo, no es algo que viene a invadir lo popular desde fuera, si es efectivamente un desarrollo de ciertas potencialidades ya existentes dentro de lo popular mismo' (de Certeau, 1988), lo que se está definiendo con esto es una mezcla de las tradiciones populares con el imaginario de las masas. Esto no significa que sean idénticas. Lo que tendría que investigarse son los códigos particulares de percepción y reconocimiento que memorias populares específicas traen a la recepción de los medios de comunicación y a los aspectos particulares de las tradiciones populares que están incluidas - de hecho transformadas - como género, estilo o tema en los medios de comunicación" (ALFARO, 1999, p. 464).
}

discurso patrio que se funda en los padres libertadores y que se cultiva desde los albores de la historia republicana, hay también un discurso paralelo, "matrio", que rescata la figura de la mujer que participó en los procesos de emancipación. Claramente se trata de una representación dispar: mientras ellos son sujetos centrales del discurso histórico oficial, ellas son relegadas a otras formas de imaginación, las que se vinculan tradicionalmente, desde el mismo siglo XIX, con la cultura popular y la cultura de masas ${ }^{3}$.

El tipo de representación que suele contener a las heroínas de la patria es del mismo cuño que distingue Beatriz Sarlo para las "narraciones semanales", obras de ficción breves producidas masivamente en Argentina a comienzos del siglo pasado:

La cuestión femenina aparece en estas narraciones sólo como cuestión de los afectos. Sin embargo, el lugar de la mujer es narrativamente exaltado, porque se la presenta como señora (aunque también esclava) de pasiones arrolladoras: rodeada por las solicitudes del futuro amante, el personaje femenino es objeto de atenciones y cuidados. Una vez que se ha fijado su lugar, se lo convierte en el objeto amado dulce o apasionadamente, aunque también en objeto sobre el que se ejerce la crueldad o el abandono (SARLO, 2011, p. 24).

Las representaciones melodramáticas de las heroínas de las historias patrias, así como lo hacen las "narraciones semanales", ponen a la mujer y sus conflictos amorosos en el medio de la acción. Este centramiento, sin embargo, no es unívoco. Se trata de representaciones que, por una parte, reconocen al sujeto femenino, pero que al mismo tiempo lo incorporan en un discurso "de segundo orden". Contienen lo que no cabe en la historiografía patriarcal probablemente porque no responde al modelo femenino instituido por esta - y simultáneamente lo traducen, reducen o regulan dentro de otros márgenes que sí parecen ser adecuados para comprender la función de la mujer en las historias nacionales de corte claramente belicista. Observamos en las representaciones decimonónicas y también en las contemporáneas la misma inclinación a leer la presencia femenina en los hechos históricos desde una clave amorosa, minimizando hasta cierto punto la faceta política de las insurgentes. Las dos mujeres de las que nos ocuparemos, Manuela Sáenz y Leona Vicario, tienen en común su relación sentimental con un prócer: la primera es la más famosa amante de Simón Bolívar y la segunda es la devota esposa de un destacado patriota mexicano, Andrés Quintana Roo. Las dos heroínas, en consecuencia, aparecen en la historia con un protagonismo relativo o de segunda categoría, aunque se les reconozca como personalidades de gran valor. Dicha interpretación, 
sin embargo, no agota el fenómeno, porque el juego de reconocimiento y control propio del melodrama tiene también implicancias culturales.

En un nivel superficial, esta forma melodramática de caracterización del sujeto femenino y sus acciones, si bien implica un gesto relevante de visiblización, no logra promover un verdadero desplazamiento en la manera que se los comprende. El "discurso amoroso", tan caro a las variadas formas de representación que veremos más adelante, relega a la mujer a su condición femenil de acompañante, de modo que se mantiene vigente el dicho: "detrás de un gran hombre hay siempre una gran mujer". Por otra parte, sin embargo, en un segundo nivel de lectura, la forma melodramática burla, con las "tretas del débil" - hago aquí un uso interesado de la expresión de Josefina Ludmer -, al discurso estandarizado característico de las historias patrias, en tanto el melodrama tiene en el contexto latinoamericano una significación especial que va más allá de las funciones culturales asociadas al modelo europeo.

Si hacemos caso a la interpretación que propone Herman Herlinghaus, en la imaginación melodramática aparecen las fuerzas de un inconsciente colectivo que está buscando nuevas formas de expresión. Según el crítico, "[un]a vez desprovisto de su estigmatización estética, el melodrama puede generar sus propias formas de reflexividad...". Estas formas se distancian notablemente de los grandes relatos de carácter oficial, pues "[s]e trata de prácticas cuyo producto característico no consiste (...) en la realización o el fracaso de los grandes objetivos y principios, sino en las historias que se están creando dentro de la precariedad del actuar humano", lo que da cabida a interpretaciones alternativas, generadas lejos de los centros de poder.

Herlinghaus entiende el melodrama como un rito de iniciación en la modernidad, en que el personaje femenino, en busca de su identidad emocional y sexual, se mueve entre la liberación y el conformismo. Estos movimientos - que conectan el amor con el problema de su legitimidad social - se expresan a través de un lenguaje sentimental, corporal y performativo, en suma, excesivo, que lo aleja de las formas de representación burguesas. En el exceso del melodrama radica, precisamente, su potencial emancipatorio respecto de los discursos sociales con pretensión de hegemonía:

Si el 'discurso' es entendible como 'realización' del lenguaje, el melodrama produce un desorden lingüístico por la intensidad de los afectos, el exceso semiótico y los mecanismos de repetición. En el melodrama, un 'más' en términos de intensidad somática y dramática, tiende a producir un 'menos' en cuanto a figuración discursiva, perteneciendo a condiciones de subjetividad poco normativas (HERLINGHAUS, 2002, p. 28-29).
Por esto mismo, es un dispositivo socio-simbólico (una matriz) cuyo estatus es performativo y narrativo a la vez, ya que no tiene discurso en términos de autoría, sistematicidad e institución (HERLINGHAUS, 2002, p. 51). Se constituye así como una fuerza imaginaria de resistencia, que genera una interpretación paralela.

Pongamos a prueba estas consideraciones sobre el melodrama, tomando en cuenta sus tensiones internas, en un acotado pero significativo corpus que representa la heroicidad de las madres de la patria. Se trata de un conjunto de obras contemporáneas, que concentran el protagonismo en las mujeres de las gestas independentistas, particularmente Manuela Sáenz y Leona Vicario, interpretando desde una perspectiva temporal amplia su participación en los procesos históricos. Son obras ficcionales que dialogan con la historiografía latinoamericana, pero cuyo fin es modificar, desde las estrategias narrativas del melodrama, sus sentidos.

2. La "heroína" que ha producido la mayor constelación representacional en torno de su figura es sin duda Manuela Sáenz, la compañera de Simón Bolívar. Nacida en Quito como hija natural de un poderoso funcionario de la corona, se casa tempranamente con un hombre al que no ama, a quien deja para seguir en su periplo guerrero al libertador. Este acto de arrojo - muy melodramático, por lo demás - y su importancia como consejera y confidente de Bolívar, le han hecho granjearse un lugar controvertido en la historia. La encontramos representada como una madre de la patria, especialmente después de la intervención simbólica de Hugo Chávez sobre la historia oficial de Venezuela, y, en el otro extremo, como una ninfómana irredenta más aficionada al sexo que a la causa política de la emancipación, en la versión novelesca de Dénzil Romero, significativamente titulada La esposa del Dr. Thorne. Entre uno y otro polo aparece idealizada o humanizada con mayor o menor énfasis, pero siempre al borde del exceso. La crítica coincide en señalar que su personalidad la dejó al margen del discurso histórico canónico sobre las independencias, ausencia que ha sido significativamente llenada por otras formas de imaginación.

El amplio corpus literario que se ha gestado en torno a Manuela puede ser visto como una serie de intentos por generar un espacio en el campo representacional para una olvidada. La libertadora protagoniza una importante cantidad de obras narrativas, dramáticas y fílmicas que generan un centramiento alternativo para el sujeto femenino. Esta nueva posición es otorgada por una forma popular de recuperación del pasado histórico, de carácter narrativo en vez de discursivo, que muchas veces acude a la imaginación melodramática para estructurar la trama explicativa de la vida de Manuela. Como no 
es posible agotar el campo de análisis, nos centraremos fundamentalmente en dos versiones: la película Manuela Sáenz, la libertadora del libertador, producción venezolana dirigida por Diego Rísquez y estrenada en 2000, y la novela Manuela, escrita por el ecuatoriano Luis Zúñiga y publicada por primera vez en 1991. En ellas veremos la operación ambivalente de los elementos del melodrama, que funcionan como refuerzo de los estereotipos femeninos, pero al mismo tiempo cuestionan los relatos patrios.

En la película de Rísquez hay dos antecedentes externos que se relacionan directamente con el modelo melodramático escogido para representar al personaje histórico: el guionista es Leonardo Padrón, poeta y autor de telenovelas, y quien desempeña el rol protagónico de Manuela es Beatriz Valdez, una conocida actriz de este tipo de producciones. La película, por tanto, dialoga con una de las formas más populares del melodrama contemporáneo: la teleserie. Este diálogo sucede tanto a nivel de estructura - por la experiencia de Padrón en el género - como a nivel de su recepción - por las resonancias melodramáticas que la propia actriz convoca.

En cuanto a su estructura narrativa, la película se mueve en dos tiempos: comienza con un barco que se aproxima a al puerto peruano de Paita (donde Manuela vive sus últimos años en el exilio), portando una peste que asolará al pueblo. El tripulante-narrador de esta historia es el ballenero y aspirante a escritor Herman Melville. El inglés se interesa por conocer a la famosa Manuela, de quien ha oído hablar, y la visita. Se encuentra con una mujer mayor, que está postrada en una silla de ruedas, y que vive del recuerdo de su gran amor por Bolívar. Desde este marco temporal, en coloración sepia, se recupera el pasado lejano, que se representa a todo color. La inversión de los códigos visuales que convencionalmente se asocian al momento del recordar y al momento del recuerdo se explica y se intensifica con el contenido del primer diálogo entre los personajes. Cuando Melville pregunta “¿Es usted Manuela Sáenz?”, ella responde: "No, yo sólo soy su sombra". Esta expresión tiene al menos dos sentidos: por una parte, ella se presenta a sí misma como la sombra de lo que fue, como un reflejo degradado de sí misma, y, por otra, nos indica que es desde la sombra (la desprovisión, la enfermedad y la vejez) que recupera el pasado vívido e intenso, marcado completamente por su vínculo con Bolívar.

Reproduzco uno de los diálogos iniciales que marcan claramente la pauta melodramática:

- ¿Y para qué quiere conocer estos escombros de la historia?

- Siempre me han interesado las leyendas y usted es una leyenda.
- Una leyenda negra.

- Yo pensaba que usted estaba muerta.

- Hace veintiséis años que estoy muerta, navegante.

Hace veintiséis años que se murió el libertador y los demás pensaron que yo también debía morir. Y aquí estoy (escupe la punta de un puro), muerta. Y qué quiere de mí. No, no lo diga. Lo mismo que todos los que entran por esa puerta: el pasado. Pero pierde su tiempo, caballero. Manuela Sáenz no habla sobre el pasado. Yo soy esto que usted ve, una mujer entrada en carnes, vieja, inválida y arrojada a un rincón del mundo, y si es por Bolívar, bástele saber que vivo lo amé y muerto lo venero.

Después de esta declaración radical de dependencia, pues Manuela se considera a sí misma "muerta" desde el fallecimiento de Bolívar, la historia retrocede a 1822, al momento en que comienza el romance entre ambos. Su relación está marcada desde el inicio por la pasión: se conocen en una fiesta y tienen inmediatamente, sin solución de continuidad, un encuentro sexual. Después de bailar en público, se reúnen en un salón privado. Él, melodramáticamente, quiebra dos copas que tenía en sus manos para brindar, toma de la cintura a Manuela y la besa. Desde esta escena en adelante, la historia es vista a través de los avatares de la relación amorosa: los hechos políticos pierden relevancia frente a los detalles íntimos, sin que se plantee entre ellos necesariamente una vinculación. Desde esta perspectiva, es claro el predominio del modelo melodramático clásico, sin mayor cuestionamiento a la historia oficial. Las cartas entre Manuela y Bolívar - recurso que funciona en la película como puente que une ambos tiempos, el pasado colorido y el sepia actual - refuerzan esta matriz, en la medida que los pasajes que se rescatan son los más íntimos, los que se refieren directamente a los avatares de su pasión. Después de la entrevista con Melville vendrán otros personajes en busca del pasado y Manuela accederá a relatarlo, de modo que el contrapunto entre ambos tiempos se mantiene activo durante todo el film. Vemos alterativamente a la Manuela joven - quien es concupisciente, atrevida y alocada - seguir a Bolívar con amor irrestricto, a pesar de sus infidelidades y su distancia, y a la Manuela anciana, quien lo recuerda con máxima añoranza en su vejez.

Si bien el amor y su consecución son el motor del sujeto femenino, hay algunos pocos elementos en la representación fílmica que desdibujan hasta cierto punto el modelo de la heroína de melodrama, agregándole un componente activo ${ }^{4}$. Algunos de estos detalles son

\footnotetext{
4 Como bien dice Lander, sin embargo, el objetivo desestabilizador no se logra: “...aunque el film cuestione los binarismos hegemónicos de las actuaciones masculinas y femeninas en la esfera de la política, y su propósito consiste en realzar la figura de Manuela como agente activo de la historia grancolombiana, su éxito es discutible. Ello se debe a que no permite ningún cuestionamiento de la condición de líder de Bolívar ni en la guerra ni en la cama (LANDER, 2011, p. 177).
} 
tomados de las anécdotas históricas, como la escena en que Manuela aparece vestida de militar y le exige a los oficiales de Bolívar que la dejen verlo (claro gesto de empoderamiento, pero a través de la masculinización del sujeto femenino), y otros son más arriesgados, como la escena de atracción lésbica con una de sus esclavas. En esta última, Manuela se encuentra desnuda, bañándose, mientras su esclava la acaricia y le habla con amor. El tema principal de la conversación es, sin embargo, Bolívar, por lo que el gesto libertario queda inmediatamente controlado. El final de la película es quizás la parte que más abre la interpretación melodramática al retroceder a tiempos anteriores a 1822. En una sucesión de escenas muy breves y vertiginosas se nos muestra por primera vez el proceso de formación del personaje, que deja entrever el surgimiento de un sujeto político autónomo: su niñez y adolescencia, marcadas por la orfandad materna y la difícil relación con el padre.

La novela de Zúñiga, por su parte, si bien recupera el formato melodramático en algunos puntos centrales la vida de la heroína también depende en esta versión de su necesidad de amor-, incorpora una mayor cantidad de matices. Manuela es la voz narrativa que recupera su historia desde la vejez, con una sabiduría que no está presente en la protagonista de la película. El novelista, desplazándose en algún grado del modelo, propone una voz femenina consciente, cuyo carácter de sujeto político queda claro no solo a través de sus acciones, sino de sus pensamientos. Al comienzo de su relato explicita Manuela: "Mis enemigos han usado todos los epítetos imaginables para condenarme, por el sólo hecho de amar a libertad y ser consecuente con el ideal de la gran nación" (ZÚÑIGA, 1997, p. 12). Sintomáticamente, Bolívar aparece recién en la página ochenta de la novela, gesto que le da relevancia al sujeto y su periplo personal, con independencia de su relación con el prócer. La imaginación melodramática, sin embargo, sigue siendo el soporte explicativo más importante de las acciones del sujeto, como puede apreciarse en esta cita que recoge el comienzo del romance:

Se acercó a mí para acariciar mi rostro; topó suavemente mis labios. Le mire en silencio; podía leer toda una historia en sus penetrantes ojos y en las arrugas que le atravesaban la frente. - Manuela..., compartamos este hermoso silencio - me dijo besando mis párpados con ternura. Un gran escalofrío recorrió mi cuerpo; lo abracé con fuerza como si temiera caerme a un abismo. Nos besamos prolongadamente. $\mathrm{Su}$ respiración se agitaba. Ambos queríamos poseernos. Caminamos a su alcoba desde la sala contigua: dejé caer mi capa y comencé a desatar mis cabellos. Un solo candelabro proyectaba nuestras sombras en la pared mientras nos desnudábamos; éramos solamente dos sombras cuando nos unimos" (ZÚÑIGA, 1997, p. 85-86).
Son varias las escenas que repiten esta estética, situando en el centro de la narración la trama amorosa, pero como decíamos más arriba, uno de los aciertos de la novela es que nos enfrenta a la ambivalencia del modelo. Si bien el melodrama pasional sigue en pie y goza de buena salud, marcando la pauta general de la relación entre Manuela y Bolívar, tanto la voz consciente de la protagonista como otros recursos presentados por Zúñiga lo desestabilizan. Uno de estos recursos es la parodia del melodrama: la novela contiene al menos dos situaciones que pueden ser leídas en clave irónica. La primera de ellas es la actuación de doña Micaela Vargas, quien, según refiere Manuela, le relata graciosamente a una audiencia sus amores con el virrey Manuel de Amar. La segunda es la actuación de la propia Manuela, cuando es detenida por una patrulla nocturna en Lima, una noche en que está repartiendo panfletos. Ella finge estar en medio de una situación muy trágica -razón por la cual merodea por la ciudad con toque de queda-; implora y solloza para convencer a los soldados. Manuela concluye, satisfecha: "Una vez a salvo en el zaguán de la casa del conde De la Vega del Ren me tranquilicé, felicitándome yo misma por el éxito de aquella comedia representada pocas cuadras atrás" (ZÚÑIGA, 1997, p. 65).

El hecho de que el texto parodie a su modelo principal contribuye a la relativización del lugar de la heroína como sujeto pasivo, representante de la parte femenina de la relación. Manuela valora y hace uso de la pantomima melodramática, excesiva, para su propio beneficio. Desde esta perspectiva, la novela permite el surgimiento de un nuevo escorzo en la caracterización del personaje histórico, quien sabe aprovechar su condición de mujer para burlar al enemigo.

Otro rasgo narrativo que desestabiliza al melodrama y contribuye a movilizar la interpretación histórica de Manuela tiene que ver con una de sus costumbres, que también aparece en la película de Rísquez: el vestirse de hombre. La Manuela Sáenz histórica solía llevar uniforme militar, hecho que causaba controversias en su tiempo ${ }^{5}$. Este referente concreto se transforma en la novela en símbolo de su empoderamiento masculino. Es también un exceso, como la desbordante feminidad que el personaje derrocha frente a su amado, y quizás en ese sentido también pueda ser visto como un elemento melodramático, pero me parece que funciona en oposición al modelo femenino por excelencia, a "la dama" o "la señorita”, personaje esquemático en el melodrama. Esta función opuesta la apreciamos, por ejemplo, cuando Manuela detiene una manifestación en contra de Bolívar en la Plaza Mayor de su ciudad natal: “... el suceso se

\footnotetext{
5 Hay otras mujeres célebres de la historia de las independencias que vistieron de hombres, entre ellas Rosario Puga y Juana Manuela Gorriti.
} 
convirtió en el comentario general de los quiteños. Las mujeres de Quito no entendían cómo una mujer vestida de militar había intervenido intentando sofocar semejante revuelta. Para todos, yo estaba completamente perdida el juicio; era la desquiciada que le gustaba provocar escándalos" (ZÚÑIIGA, 1997, p. 97). Los comentarios de este tenor se repiten varias veces: ella se diferencia de las demás mujeres de clase alta, incluso de las patriotas, porque actualiza su potencia masculina. Manuela, sin embargo, no está sola. Se equipara a las mujeres de los soldados humildes que siguen a los ejércitos para suplir sus necesidades. Respecto de ellas y de sí misma, dice: "Hay quienes han nacido para tejes encajes, y otras para galopar en el fuego..." (ZÚÑIGA, 1997, p. 107).

La novela sigue el periplo de la Manuela Sáenz histórica concentrándose en los años en que es pareja de Bolívar, pero también se preocupa de representarla antes y después de dicha relación. Zúñiga genera así un personaje femenino más completo, que goza de cierta independencia, no solo física, sino de pensamiento. Las palabras finales de Manuela están en consonancia con los desplazamientos del modelo melodramático que hemos evidenciado; su momento histórico es un momento de excepción:

No me arrepiento de mis actuaciones - dice Manuela -. Los tiempos que me ha tocado vivir han sido duros, y yo he actuado con la misma dureza ante diferentes circunstancias. Todo sacrificio realizado lo he asumido como un deber. En fin, el tiempo me justificará (ZÚÑIGA, 1997, p. 181).

3. Así como hay representaciones melodramáticas más conservadoras o más abiertas de Manuela Sáenz, otras heroínas de la patria, como Leona Vicario, pasan por un proceso de elaboración imaginaria similar. El melodrama nuevamente aparece como modelo estético generador de sentidos históricos, dando cuenta de variantes similares a las que hemos visto hasta ahora. Es lo que sucede en la historieta Leona Vicario de Quintana Roo, la dama de la independencia (1960), escrita por Francisco Gurza e ilustrada por Antonio Gutiérrez, y la novela La Insurgenta (2010) de Carlos Pascual. Cuarenta años separan a una representación de otra, lo que se percibe también en su forma de hacerse cargo del personaje femenino: en el cómic prima el melodrama en su función política de control de la emocionalidad femenina; en la novela, en cambio, el modelo se complejiza notablemente.

Llama la atención, desde el título de la historieta, que se escoja llamar a la madre de la patria mexicana con el apellido de su esposo: ella es Leona Vicario de Quintana Roo. El hecho de que se le dedique un número completo en la colección Biografías Selectas es, sin embargo, un gesto de reconocimiento notable. Hasta el día de hoy, Leona Vicario es poco conocida por los mismos mexicanos, quienes, como dice Carlos Pascual, la recuerdan solo por una anécdota: en medio de la revolución de independencia, habría parido a su hija en una cueva.

El cómic ciertamente saca al personaje del relativo anonimato, pero la forma en que lo hace es neutral. La historia de Leona está marcada por la relación amorosa que sostiene con su marido; es más, su patriotismo se justifica por amor. Aun cuando ella tiene una vida previa, que se desarrolla con detalles antes de conocer a Quintana Roo, parece más bien un periplo preparatorio. Queda huérfana siendo muy niña, a cargo de un tío que la educa de manera inusual para las mujeres de su tiempo. Cuando ya es una joven, aburrida del encierro doméstico, va a trabajar al bufete de su tío. Su ingreso al mundo laboral no tiene que ver, necesariamente, con su necesidad de cultivarse o hacer algo útil, sino más bien de conectarse con otras personas.

Una vez en el bufete de su tío surgen los problemas. Sus colegas hombres la observan desde lejos y opinan:

- Ya no podremos trabajar con esa mujer bonita tan cerca...

- ¡Claro! Las mujeres deben quedarse en casa.

- No tienen derecho a invadir un terreno que nos pertenece (GURZA, 1960, p. 13).

El único que se opone a esta visión machista es Quintana Roo, quien defiende el hecho que las mujeres participen del mundo intelectual y del trabajo: "Se equivocan, amigos míos: desde que la Revolución Francesa impuso las normas de libertad, igualdad y fraternidad, las mujeres tienen derechos que antes se les negaban”, “...la señorita Vicario, que además de hermosa es inteligente podría llegar a ser la iniciadora del movimiento libertador de su sexo" (GURZA, 1960, p. 13). Su mentalidad progresista, sin embargo, tiene un límite, en tanto él se arroga el papel del mentor: "Adivino las bellezas de su espíritu incultivado aún, y sólo aspiro a inculcar en él, las ideas que podrían hacer de ella una heroína" (GURZA, 1960, p. 13). Aquí el cómic reordena los esquemas patriarcales, pues es el hombre quien educa e ilumina.

Pocas viñetas después asistimos al nacimiento de la conciencia política de Leona, cuando nota las injusticias de la corona. Esta conciencia, sin embargo, aparece mediada por Quintana Roo: "Déjate guiar por mí en esta batalla, y preparémonos para cuando llegue el momento" (GURZA, 1960, p. 15). Ella, sumisamente, contesta: "Sí, Andrés" (GURZA, 1960, p. 15). Desde aquí en adelante queda fijada la jerarquía entre ambos: ella es un sujeto con un pensamiento político en bruto que necesita de 
un hombre que le dé sentido a su reflexión. Lo mismo sucede al poco andar con su comportamiento. Leona se transforma en una activista, pero siempre motivada por el amor. Cuando Quintana Roo decide partir a la revolución, ella le implora: "Estoy tan identificada con tus afanes, pensamientos y trabajos, que sólo vivo por ti. ¡Llévame contigo, Andrés! Serviré en el campo insurgente..." (GURZA, 1960, p. 22). Por petición del tío, ella se queda, pero se compromete a colaborar desde su posición: "Lo haré por ti y por la patria" (GURZA, 1960, p. 22). Nótese que el primer motor es el amado; el segundo, el patriotismo.

Luego de muchos avatares, que incluyen el haber estado presa en manos de la Inquisición, Leona cumple su máximo anhelo, que es casarse con Andrés. Después de una breve ceremonia, deben reintegrase a la lucha. Vestida de novia, ella declara: "Yo iré con mi marido" (GURZA, 1960, p. 28). De allí en adelante la historieta reseña varios de los episodios de su participación en la independencia mexicana, hasta los momentos finales de la vida de la heroína. Ella ha sido llamada por el Congreso para recibir una condecoración especial, pero le pide a su marido que vaya por ella: "Ve tú en mi lugar, Andrés, y recoge toda la gloria, dejando para mí la tranquilidad de este retiro, que es lo único que quiero..." (GURZA, 1960, p. 31). A lo que agrega una voz en off: "Y así fue, porque doña leona consideró terminada su tarea de heroína, y sólo deseaba completar su misión de mujer en la paz del hogar" (GURZA, 1960, p. 31). En la viñeta final del cómic, en consonancia con el modelo melodramático más clásico, Leona aparece en el momento de su muerte llamando a su marido. Lo último que dice es “¡An...drés...!” (GURZA, 1960, p. 32). Sin comentarios.

Como adelantábamos, la novela de Carlos Pascual, La insurgenta, presenta muchos más matices. Es la única de las narraciones que hemos visto hasta ahora que se abre a distintas perspectivas. Su estructura es polifónica; en ella intervienen múltiples voces de testigos que llegan a un tribunal a dar su opinión acerca de la pertinencia de nombrar a Leona como "Benemérita y Dulcísima Madre de la Patria" mexicana. Sobre la base de este hecho histórico - Leona efectivamente tuvo Funerales de Estado y se le otorgó ese título - la novela ficcionaliza las posibles opiniones que podría haber suscitado en su tiempo el comportamiento de esta particular mujer. Será alabada y criticada indistintamente, apareciendo con rasgos sobresalientes y también muy humanos, y no siempre se la observará en su vinculación con Quintana Roo. Esta propuesta que, como veremos a continuación, oscila mayormente entre la interpretación melodramática del personaje femenino y su masculinización - en la misma clave que propone Zúñiga para Manuela -, aporta a fin de cuentas una visión mucho más original de la heroína, que discute abiertamente con el modelo. Avanzaremos en el orden de exposición de los testimonios, rescatando los más relevantes para nuestra línea de lectura, con el fin de mostrar cómo funciona el contrapunto.

Al comienzo de la novela, uno sus detractores justifica su decisión de votar a favor del nombramiento basándose en la "hombría" de Leona. Al igual que en el caso de Manuela, el personaje femenino activo es interpretado en clave masculina: “ $¡$ Porque era valiente! ¡Porque tenía cojones! (...) ¿Ustedes creerían que esta... esta... la Vicario, que no era mayor de veinte años, no tembló ni un ápice ante mi presencia? (...) Hombre más bragados he visto yo quebrarse y llorar como un niño..."6 Esta visión potente, levantada por el juez que la interroga en el Tribunal del Santo Oficio, al poco andar será discutida. Antonia Navia, amiga de Leona y cómplice en algunas aventuras insurgentes, abogará por considerarla en su faceta femenina y por incorporarla a la historia en su calidad de mujer: "Un hombre, por el hecho de ser hombre, pasará a la Historia tan sólo por un mínimo acto de heroísmo. Tiene que ser, como fue la de doña Leona, una labor titánica, una de toda la vida para ser reconocida".

La cocinera de la casa, Rita, es la encargada de transmitir, aunque de manera indirecta, el romance entre Leona y Andrés, incorporando el elemento melodramático. Cuenta acerca de las dificultades de su amor, a las que ella contribuye. Señala que los enamorados conversaban mucho sobre cosas elevadas, lo que a la cocinera no le parecía necesario: "Porque el amor no se dice y mucho menos se entiende. El amor se siente y se ve y se desborda por los ojos, iy una huele a amor! Y el amor huele a fruta fresca, a eso olían los dos, a manzanas. Y por eso le tenía envidia a la niña Leona". Continuando con el juego de contrapuntos, unas páginas más adelante, el tratamiento femenino de la heroína se disipa y nuevamente es masculinizada. El coronel que la ayudó a escapar del convento donde estuvo detenida, quien la admira sobremanera, opina: "Jamás habré de olvidar la determinación de doña Leona Vicario, señores. Es una pena, también dicho con todo respeto, que hubiese nacido mujer. Qué gran militar habría sido doña Leona".

En un testimonio posterior, consecuentemente, se recupera la mirada melodramática: el periodista Guillermo Prieto, colega de Andrés, la reduce a su función de esposa:

La señora Quintana (...) hizo lo que toda buena mujer mexicana hubiera podido hacer: luchar a brazo partido en el apoyo de su esposo, en el amor a su patria y, finalmente, una vez terminados los tiempos, retomar su sagrado espacio en el hogar y en la educación de sus hijas.

\footnotetext{
6 Estas citas han sido tomadas de un ebook, por lo que no es posible determinar el número de página.
} 
Nótese que la identifica completamente con su apellido de casada y que considera su intervención en la independencia subordinada a la figura de su marido; se mueve en el mismo registro de neutralización que veíamos en la historieta. La Güera Rodríguez, personaje emblemático de la independencia mexicana, también la verá como una subordinada, pero no valorará esos gestos del personaje: "Leona tenía una pluma y sí, en su momento, también una espada, pero decidió cambiarlas por un bordado y un rosario". Finalmente, el general Víctor Bravo dará en su testimonio un giro valorativo sobre el móvil del amor, devolviendo la interpretación al modelo melodramático:

\begin{abstract}
Allí estaba ella, con su juventud, su inteligencia magnífica, (...) convertida en una amazona enamorada de don Andrés, el hombre más envidiado de todos en aquel entonces, porque sí, no puedo negarlo y no me importa a esta edad ser considerado un romántico empedernido, pero la historia de doña Leona y de don Andrés, aun así que nos resulte extraño, es una historia de amor.
\end{abstract}

Según él, Leona trabaja en las sombras, editando e incluso redactando muchos de los artículos publicados por los revolucionarios. La reconoce como un gran personaje histórico, pero que se ubica, como corresponde a su naturaleza femenina, detrás de su marido.

En medio de la novela, ubicado en el corazón del contrapunto entre el melodrama reductor y la visión masculinizada de la protagonista, se rescatan las palabras de la propia Leona Vicario. Se lee su carta en en respuesta a las críticas de Lucas Alamán, quien la ha comparado con "una vulgar heroína de novela romántica". Esta extensa cita a un documento histórico real funciona como un punto de equilibrio entre las interpretaciones oscilantes que hemos visto hasta ahora, y que continúan luego en el resto de la novela. Podría decirse que es como el ojo del huracán, un momento de lucidez en medio en la polifonía de voces que da cuenta de la imposibilidad de situar al sujeto. Recogemos la parte más relevante, que discute abiertamente con el modelo melodramático, resquebrajándolo desde dentro:

Si cree usted que el amor fue el móvil de mis acciones, ¿qué conexión pudo haber tenido este con la firmeza que manifesté ocultando, como debía, los nombres de los individuos que escribían por mi conducto, siendo que ninguno de ellos era mi amante? Confiese Ud., Sr. Alamán, que no sólo el amor es móvil de las acciones de las mujeres: que ellas son capaces de todos los entusiasmos, y que los deseos de la gloria y de la libertad de la patria no les son unos sentimientos extraños (...). Si Madame de Staël atribuye algunas acciones de patriotismo a la pasión amorosa en las mujeres, esto no probará jamás que sean incapaces de ser patriotas, cuando el amor no las estimula a que lo sean. Por lo que a mí toca, sé decir que mis acciones y opiniones han sido siempre muy libres, nadie ha influido absolutamente en ellas, y en este punto he obrado siempre con total independencia...

La voz de la propia Leona histórica es la que advierte sobre el reduccionismo que suele llevar implícito el melodrama en su versión más estereotipada. Hacer depender las acciones de un personaje femenino de sus sentimientos amorosos es cercenar su potencialidad política; es, como decíamos al principio, una forma de ejercer control sobre el sujeto que no se adecua a los parámetros sociales establecidos para lo femenino. La novela, sin embargo, da cabida en su seno y despliega las potencialidades del melodrama, ya sea porque es necesario para entender la forma en que una comunidad construye un personaje histórico femenino, o porque se reconoce su potencia desacralizadora. Lo cierto es que la insurrecta Leona Vicario permanece, después de la versión de Pascual, en esa curiosa ambivalencia que caracteriza al modelo.

4. Son muchas las conclusiones que pueden sacarse de este recorrido intermedial de tono melodramático por las obras que representan a dos grandes mujeres del XIX latinoamericano. Resumiremos aquí las más relevantes, en virtud del hilo conductor que hemos propuesto para observarlas: la forma en que se apropian de los recursos del melodrama para reformularlos.

Lo primero que hay que señalar es que existe una gradación sintomática en el apego al modelo: la historieta sobre Leona, que es la obra más distante en el tiempo, es también la más fiel al melodrama. Podemos entender que en 1960 la cultura latinoamericana sigue siendo bastante conservadora en lo tocante a los estereotipos femeninos: el modelo de buena esposa y madre ejemplar es todavía el más apreciado. Este rasgo contextual, sin embargo, no necesariamente es determinante. En el caso de las representaciones de Manuela, por ejemplo, es mucho más rupturista la novela de Zúñiga, publicada en 1991, que el film de Rísquez que data del 2000. El criterio cronológico, por tanto, es relativo, por lo que habría que buscar en otra parte las causas de la diferencia en el tratamiento melodramático.

Una segunda explicación posible tiene que ver con el carácter masivo de las obras revisadas. Tanto la historieta como la película están mucho más cerca que las novelas de los medios de comunicación masivos. De hecho, el cine y el cómic pertenecen a las formas híbridas del siglo XX, que son a su vez artísticas y de entretención, lo que los hace proclives a la mantención del melodrama en sus niveles interpretativos más básicos. La misma 
función cumplía - podría argüirse - la novela durante el siglo XIX, y sigue cumpliendo hasta el día de hoy, aun cuando se haya sofisticado. Es más, ambas novelas han tenido un éxito editorial importante: Manuela cuenta con varias ediciones y La insurgenta ganó el premio Grijalbo de Novela en 2010. Desde ese punto de vista, son tan masivas como las otras formas de representación.

Lo que sí es efectivo, es que tanto en la película sobre Manuela como en la historieta sobre Leona la imagen femenina calza con algún estereotipo: la amante y la esposa respectivamente. Las novelas, por su parte, complejizan la representación, desdibujando los límites del melodrama al incluirlo y parodiarlo. Cabe consignar, además, que ambos textos insisten en otras formas de aproximación al personaje histórico, poniendo énfasis en su masculinización. Este procedimiento, si bien se encuentra en la película, no tiene el mismo efecto. El afiche del film representa a Manuela vestida como dama $y$, reflejada en un espejo, su imagen con traje de oficial; pero este recurso, asociado a una posible dualidad del personaje, no se desarrolla mayormente.

Lo que parece más acertado es juzgar los textos en su contexto inmediato para valorar las formas en que estas representaciones resitúan a las mujeres de la independencia dentro de la imaginación histórica latinoamericana. Desde este punto de vista, el hecho de que un cómic de los años sesenta se haga cargo de una figura femenina poco presente en los textos escolares de historia constituye un tremendo logro. Después de él, no se rescatará masivamente a la heroína. Leona Vicario surge como un sujeto histórico relevante recién en los alrededores del bicentenario de la independencia de México, momento en que aparece la obra de Pascual. El grado de trabajo sobre la imagen de la insurgenta es mayor y por lo mismo es posible, quizás, intervenir y complejizar el modelo melodramático.

La novela de Zúñiga se gesta en un momento literario muy particular en América Latina, marcado por la aparición de un tipo de narrativa de tema historiográfico revisionista, que toma sucesos del pasado latinoamericano para reescribirlos críticamente. Este subgénero, conocido como nueva novela histórica, se asocia a la controvertida efeméride de los 500 años del "descubrimiento" de América, pero también se irradia a otros momentos de las historiografías nacionales, como los procesos de emancipación. Dentro de este contexto, la tarea de Zúñiga aparece apoyada por un corpus sustancioso de representaciones ficcionales cuya preocupación son los personajes y los sucesos históricos. Su propuesta narrativa, sin embargo, se diferencia de estas, por cuanto escoge otros modos de representación, como el melodrama, que tendrán mayor desarrollo hacia finales de la misma década. Aún falta un estudio comparativo de este tipo, pero esta novela bien podría ser la precursora de una sub-modalidad de la nueva novela histórica.

Finalmente, el film de Rísquez, si bien se ubica en un horizonte temporal próximo, no cuenta con un corpus cinematográfico de inspiración histórica importante con el que pueda establecer algunos diálogos. El cine latinoamericano que problematiza la historia es más bien reciente ${ }^{7}$; la mayor producción se concentra en torno al bicentenario de las independencias. En este corto periodo ha aparecido un número notable de películas que retoma las figuras heroicas del siglo XIX, tanto para reforzar las interpretaciones canónicas de las historias patrias, como para desestabilizarlas. Manuela Sáenz, la libertadora del libertador, por lo tanto, también se ubica en un lugar de avanzada respecto de este corpus.

Más allá de sus diferencias, estos cuatro ejemplos de utilización del modelo melodramático contribuyen, cada uno a su modo, a desestabilizar ciertas certezas repetidas de discurso en discurso respecto de la forma en que se realizaron los procesos de independencia en las naciones americanas. La propia identidad nacional, apoyada en su formación por los relatos sobre la emancipación política, se ve tocada por estos relatos otros, que rescatan aspectos del imaginario histórico muchas veces relegados al olvido. Este es el caso, sin duda, de las protagonistas mujeres, y el melodrama latinoamericano, actuando como una fuerza centrípeta, está ocupando un lugar en este proceso. Después de este recorrido no podemos sino coincidir con Herman Herlinghaus, para quien "[e]l lugar del melodrama en los procesos de 'nacionalización' imaginaria es revelador en su potencial tanto afectivo como descentrador con respecto a las pretensiones de la ciudad letrada" (HERLINGHAUS, 2002, p. 32).

\section{Referencias}

ALFARO, Salvador Orlando. Consideraciones acerca de la cultura popular. Realidad - Revista de Ciencias Sociales y Humanidades, San Salvador, n. 70, p. 457-469, jul.-agosto 1999.

BROOKS, Peter. The melodramatic imagination. New Haven, London: Yale University Press, 1976.

GURZA, Francisco; GUTIÉRREZ, Antonio. Leona Vicario de Quintana de Roo, la dama de la independencia. México: Edar, 1960.

HERLINGHAUS, Herman. Narraciones anacrónicas de la modernidad: melodrama e intermedialidad en América Latina. Santiago: Cuarto Propio, 2002.

LANDER, María F. La encrucijada de Manuela Sáenz en el imaginario cultural latinoamericano del siglo XXI. Araucaria - Revista Iberoamericana de Filosofía Política y Humanidades, Sevilla, v. 13, n. 25, p. 165-181, jul.-dic. 2011.

\footnotetext{
7 Con algunas excepciones notables, como Camila (1984) y Yo, la peor de todas (1990), ambas dirigidas por María Luisa Bemberg.
} 
LUDMER, Josefina. Las tretas del débil. In: GONZÁLES, Patricia; ORTEGA, Eliana (Eds.). La sartén por el mango. Venezuela: Ediciones Huracán, 1984.

MANUELA Sáenz: la libertadora del libertador. Dirección: Diego Rísquez. Guión: Leonardo Padrón. Producción: Pedro Mezquita Arcaya y Antonio Llerandi. Intérpretes: Beatriz Valdés; Mariano Álvarez; Erich Wildpret y otros. Música: Stefano Gramitto. Venezuela: Producciones Guakamaya, Centro Nacional Autónomo de Cinematografia, 2000. 97 min., colorido.

PASCUAL, Carlos. La insurgenta. México: Grijalbo, 2010. Ebook. ROMERO, Dénzil. La esposa del Dr. Thorne. Barcelona: Tusquets, 1988.
SARLO, Beatriz. El imperio de los sentimientos. Argentina: Siglo XXI, 2011.

SOTO, Cyntia. Mapocho: una reescritura melodramática de la historia nacional. Tesis. Universidad Diego Portales, 2013.

WHITE, Hayden. Metahistoria. México: FCE, 1992.

ZÚÑIGA, Luis. Manuela. Quito: Eskeletra Editorial, 1997.

Recebido: 10 de abril de 2014

Aprovado: 02 de junho de 2014

Contato: pizarrocortes@gmail.com 